\title{
A comparative cost analysis study of lobectomy performed via video-assisted thoracic surgery versus thoracotomy in Turkey
}

\author{
Levent Alpay ${ }^{1}$, Tunc Lacin ${ }^{1}$, Dilek Teker ${ }^{2}$, Erdal Okur ${ }^{3}$, Volkan Baysungur ${ }^{1}$, Serda Kanbur ${ }^{1}$, Aysun Kosif Misirlioglu ${ }^{1}$, \\ Hakan Sonmez ${ }^{4}$, Irfan Yalcinkaya ${ }^{1}$, Mithat Kiyak ${ }^{2}$ \\ ${ }^{1}$ Department of Thoracic Surgery, Sureyyapasa Training and Research Hospital, Istanbul, Turkey \\ ${ }^{2}$ Faculty of Economics and Administrative Sciences, Okan University, Istanbul, Turkey \\ ${ }^{3}$ Department of Thoracic Surgery, Acibadem Hospital, Istanbul, Turkey \\ ${ }^{4}$ Department of Thoracic Surgery, Sultanbeyli Hospital, Istanbul, Turkey
}

Videosurgery Miniinv 2014; 9 (3): 409-414

DOI: $10.5114 /$ wiitm.2014.44254

\begin{abstract}
Introduction: Cost analysis studies performed in western countries report that the overall cost of lobectomies performed via video-assisted thoracic surgery is similar to or less than those performed via thoracotomy. The situation may be different in a developing country.

Aim: We evaluated the cost differences of these two surgical methods.

Material and methods: We retrospectively reviewed the hospital records of 81 patients who underwent lobectomy either via video-assisted thoracic surgery $(n=32)$ or via thoracotomy $(n=49)$. Patient characteristics, pathology, perioperative complications, additional surgical procedures, length of hospital and intensive care unit stay, and outcomes of both groups were recorded. Detailed cost data for medications, anesthesia, laboratory, surgical instruments, disposable instruments and surgery cost itself were also documented. Statistical analyses were performed to compare the groups.

Results: The two groups were homogeneous in regard to age, sex, pathology and perioperative morbidity. The mean duration of hospitalization in the video-assisted thoracic surgery group was significantly shorter than that of the thoracotomy group $(7.78 \pm 5.11$ days vs. $10.65 \pm 6.57$ days, $p<0.05)$. Overall final mean cost in the video-assisted thoracic surgery group was significantly higher than that of the thoracotomy group $(\$ 3970 \pm 1873 \mathrm{vs}$. $\$ 3083 \pm 1013$, $p=0.002)$. This significant difference relies mostly on the cost of disposable surgical instruments, which were used much more in the video-assisted thoracic surgery group than the thoracotomy group $(\$ 2252 \pm 1856$ vs. $\$ 427 \pm 47$, $p<0.05)$.

Conclusions: In contrast to western countries, a video-assisted thoracic surgical lobectomy may cost more than a lobectomy via thoracotomy in a developing country. More expensive disposable surgical instruments and cheaper hospital stay charges lead to higher overall costs in video-assisted thoracic surgical lobectomy patients.
\end{abstract}

Key words: lobectomy, video-assisted thoracic surgery, thoracotomy.

\section{Introduction}

With the development of thoracic surgery, nowadays thoracic surgeons are seeking minimally invasive procedures both to increase patient comfort and to reduce the costs of interventional procedures. Thoracoscopic procedures which have come into use since 1991 are becoming more common and preferred as they are more cosmetic with a small incision, less pain and blood loss, and shorter intensive

\section{Address for correspondence}

Levent Alpay MD, Department of Thoracic Surgery, Sureyyapasa Training and Research Hospital, Basibuyuk Mah. Maltepe,

34844, Istanbul, Turkey, phone: + 90532 3310478, fax: + 90216 4214110, e-mail: leventalpay@yahoo.com 
care unit and hospital stay [1]. While thoracoscopy was used most commonly for diagnostic purposes in parenchymal and pleural lesions and for management of pleural effusions, in recent years, the proportion of thoracoscopic resections in lung cancer surgery has increased with the developments in endoscopic equipment [2-4]. However, beside the advantages, video-assisted thoracic surgery (VATS) also brings disadvantages such as increased need for disposable equipment, limited digital palpation and obscure long-term results [5].

The most effective treatment in resectable lung cancer is still lobectomy [6]. It is obvious that VATS lobectomy gives a better postoperative life quality compared to open thoracotomy. Many comparative studies report that the costs of VATS lobectomy and thoracotomy are equal or less in VATS.

\section{Aim}

We evaluated cost differences of these two surgical methods in our country.

\section{Material and methods}

We retrospectively investigated the records of 81 stage I non-small cell lung carcinoma (NSCLC) patients who underwent lobectomy in our institution between September 2007 and March 2009. Fortynine of those patients had resection via thoracotomy and 32 via VATS. Patient characteristics, perioperative complications, additional surgical procedures, their pathologies and length of hospital and intensive care unit stays were investigated. The costs for anesthesia, laboratory, medications, surgical equipment and surgery were calculated. All costs were converted to US dollar currency at the time of the study.

All patients were preoperatively assessed with history, physical examination, serum biochemistry and complete blood count, respiratory function tests, electrocardiography, chest radiography and computed tomography. None of the lung cancer patients performed with VATS or open thoracotomy had mediastinal, chest wall or major artery involvement. All lung cancer patients had preoperative histologic diagnosis. Preoperative management included positron emission tomography (PET-CT) and brain magnetic resonance imaging (MRI) to investigate distant metastasis. Mediastinoscopy for preoperative lymph node staging was performed in only 2 patients who had VATS due to negative mediastinal status on
PET-CT. In the thoracotomy group, 32 patients had mediastinoscopy to rule out suspected lymph node positivity on preoperative radiological examinations.

In the thoracotomy group, the serratus anterior muscle was spared and thoracotomy was performed via the posterolateral fifth intercostal space. The vascular structures were tied using silk sutures. The bronchus was hand-sewn using vicryl or prolene sutures. In the VATS lobectomy group, a 30-degree thoracoscope was inserted via a $10 \mathrm{~mm}$ thoracoport from the anterior axillary line in the seventh intercostal space. Two or three port incisions were used. A $4 \mathrm{~cm}$ utility incision was made through the fifth intercostal space along the anterior axillary line. Endoscopic vascular staplers were used to divide the pulmonary artery, vein and bronchus. Patients in both groups underwent systemic lymph node dissection. Patients who were converted to thoracotomy were excluded from the study.

Detailed cost data were calculated for drugs, anesthesia, laboratory tests, surgical equipment, disposable devices and surgery. Findings were reported as the group average \pm standard deviation. Cost analysis was based on invoices paid to the hospital by the Republic of Turkey Social Security Administration. The Kolmogorov-Smirnov test was applied for both techniques to test for a normal distribution.

\section{Statistical analysis}

Based on Kolmogorov-Smirnov test statistics, the thoracotomy group was compatible with a normal distribution. However, since the VATS group did not exhibit a normal distribution, the Mann-Whitney $U$ test was performed to determine whether there was a significant difference between the costs of the two techniques.

\section{Results}

Thirty-two patients among 81 who were included in the study underwent VATS lobectomy and 49 underwent lobectomy with standard posterolateral thoracotomy. Patients in each group were homogeneous in terms of sex, age, diagnosis and comorbid factors (Table I). Of the patients who underwent VATS lobectomy $(n=32), 10$ were women and 22 were men. Of those who underwent lobectomy with standard thoracotomy $(n=49), 6$ were women and 43 were men. Mean age was $66 \pm 3.8$ in the VATS group and $58 \pm 4.4$ in the thoracotomy group. Among 
the patients who underwent VATS lobectomy, 7 had benign pathology, while 25 had malignant pathologies. Among those who underwent lobectomy with standard thoracotomy, 8 patients had benign pathology whereas 41 had malignancy (Table I).

The most common comorbidities in each group were chronic obstructive pulmonary disease (COPD) and hypertension. In the VATS lobectomy group, hypertension and COPD were present as comorbid factors in $25 \%$ and $28 \%$, and in the lobectomy group with thoracotomy, $31 \%$ and $27 \%$, respectively.

Among 32 patients who underwent VATS lobectomy, 10 had left upper, 8 right upper, 7 left lower, 5 right lower and 2 middle lobectomies (Table II). Stages of all lung cancer patients in both groups were T1 or T2, NO, MO. All patients were admitted to a postoperative intensive care unit overnight following the surgery. Thirteen patients who underwent lobectomy with thoractomy stayed in the postoperative intensive care unit for 2 days, 1 patient for 3 days and 1 for 5 days. Thirty-four other patients were admitted to the ward following postoperative stay in the intensive care unit overnight. Among them, 1 patient with right lower bilobectomy needed 4 days of intensive care unit treatment for mechanical ventilation due to respiratory failure. Another patient stayed in the intensive care unit for 2 days following completion of pneumonectomy for bronchopleural fistula that developed following right upper lobectomy. The remaining 13 patients were followed in the intensive care unit for 1 day due to postoperative bleeding, pneumonia, atelectasia and for primary repair of trachea laceration due to endotracheal tube malposition. Among 32 patients who underwent VATS lobectomy, 30 were admitted to the ward following surgery. Only 2 patients needed intensive care unit stay for 1 day (1 patient for high output, 1 following revision for massive air leak). The most common complications in each group were prolonged air leak and atelectasis (7\%).

Mean hospital stay for those patients was 10.65 \pm 6.57 days. For patients who underwent VATS lobectomy, mean hospital stay was $7.78 \pm 5.11$ days. The longer hospital stay in VATS lobectomy patients in our group when compared to similar studies in the literature can be attributed to our learning curve period with VATS lobectomy. The patients who underwent lobectomy via thoracotomy had significantly longer hospital stay compared to those who underwent VATS lobectomy $(p<0.05)$. In our country
Table I. General characteristics of patients who underwent lobectomy

\begin{tabular}{|lcc|}
\hline Variables & $\begin{array}{c}\text { VATS } \\
(n=32)\end{array}$ & $\begin{array}{c}\text { Thoracotomy } \\
(n=49)\end{array}$ \\
\hline $\begin{array}{l}\text { Patient's gender } \\
\text { (male/female) }\end{array}$ & $22 / 10$ & $43 / 6$ \\
\hline Age & $66 \pm 3.8$ & $58 \pm 4.4$ \\
\hline \begin{tabular}{l} 
Diagnosis: \\
\hline Bronchiectasis
\end{tabular} & $6(19 \%)$ & $8(16 \%)$ \\
\hline Aspergilloma & $1(3 \%)$ & - \\
\hline Carcinoid tumor & $1(3 \%)$ & $3(6 \%)$ \\
\hline Adenocarcinoma & $11(34 \%)$ & $15(31 \%)$ \\
\hline Squamous cell carcinoma & $13(41 \%)$ & $23(47 \%)$ \\
\hline Hypertension & $8(25 \%)$ & $15(31 \%)$ \\
\hline Diabetes mellitus & $6(19 \%)$ & $5(10 \%)$ \\
\hline Coronary artery disease & $1(3 \%)$ & $2(4 \%)$ \\
\hline COPD & $9(28 \%)$ & $13(27 \%)$ \\
\hline Smoking & $26(81 \%)$ & $29(60 \%)$ \\
\hline FEV (\%) & $62 \pm 20$ & $70 \pm 19$ \\
\hline
\end{tabular}

COPD - chronic obstructive pulmonary disease, FEV ${ }_{1}$ - forced expiratory volume in the $1^{\text {st }} s$

Table II. Distribution of anatomic pulmonary resections and TNM stages

\begin{tabular}{|lcc|}
\hline Variables & VATS $(n=32)$ & Thoracotomy $(n=49)$ \\
\hline LUL & 10 & 13 \\
\hline RUL & 8 & 16 \\
\hline LLL & 7 & 7 \\
\hline RLL & 5 & 8 \\
\hline RML & 2 & 3 \\
\hline BLB & - & 2 \\
\hline Stage: & 10 & 6 \\
\hline T1NOMO & 14 & 32 \\
\hline T2NOMO & 10 & \\
\hline
\end{tabular}

BLB - bilobectomy, LLL - left lower lobectomy, LUL - left upper lobectomy, $R L L$ - right lower lobectomy, $R M L$ - right middle lobectomy, RUL - right upper lobectomy

hospital the bed cost for 1 day is between $\$ 10$ and $\$ 15$, which is one of the main factors why the cost for thoracotomy patients is less than that in the published literature. 
Table III. Operational costs (US dollars)

\begin{tabular}{|c|c|c|c|c|}
\hline \multirow[t]{2}{*}{ Variables } & \multicolumn{2}{|c|}{ VATS $(n=32)$} & \multicolumn{2}{|c|}{ Thoracotomy $(n=49)$} \\
\hline & Mean & Standard deviation & Mean & Standard deviation \\
\hline Postoperative drugs & 355.82 & 556.43 & 186.05 & 251.69 \\
\hline Anesthesia drugs & 101.04 & 65.5 & 94.92 & 88.76 \\
\hline Laboratory tests & 223.36 & 249.76 & 158.23 & 185.51 \\
\hline Pathology & 287.36 & 104.52 & 154.48 & 95.09 \\
\hline Anesthesia & 223.48 & 62.22 & 165.32 & 59.11 \\
\hline Surgery cost & 888.99 & 619.22 & 586.48 & 82.48 \\
\hline Anesthesia instruments & 62.98 & 30.90 & 66.49 & 29.9 \\
\hline Surgical instruments & 142.31 & 85.88 & 86.74 & 82.8 \\
\hline \multicolumn{5}{|l|}{ Disposable surgical } \\
\hline Instruments & 427 & 470.35 & 2251.78 & 1855.65 \\
\hline Ward instruments & 17.52 & 20.95 & 17.14 & 15.92 \\
\hline Ward or ICU procedures & 241.76 & 235.97 & 156.3 & 121.1 \\
\hline Total average cost* & 3083 & & 3970 & \\
\hline
\end{tabular}

ICU - intensive care unit, VATS - video-assisted thoracoscopic surgery; ${ }^{*} p=0.002$

There was no statistically significance between the two groups in terms of costs of administered drugs, laboratory tests, anesthesia or surgery. Mean total cost in the videothoracoscopic lobectomy group $(\$ 3970 \pm 1873)$ was significantly higher than that for open lobectomy $(\$ 3083 \pm 1013)(p=0.002)$. This significant difference was related to the additional cost of disposable surgical equipment $(p<0.05)$ (Table III).

\section{Discussion}

Thoracic surgeons, without compromising patient care, prefer surgical methods which reduce mortality, morbidity and the cost. Publications report that reducing hospital stay and preoperative tests significantly reduces costs. In recent literature, it is mentioned that the cost of VATS lobectomy is lower, especially in developed countries [7].

In developing countries, the main reasons for the high cost of VATS lobectomy are endostaplers and other disposable devices [7]. In the last decade, VATS lobectomy has increasingly been recommended and successfully performed in patients with early stage NSCLC [8-10], with advantages such as less postoperative pain, fewer complications and shortened hospital stay [10-14]. In cancer surgery, long-term survival of patients who underwent lobectomy via
VATS or thoracotomy showed similarities in various comparative studies and meta-analyses [15-17].

Hazelrigg et al. reported that thoracoscopic procedures have higher costs [18]. In that study, similar to ours, it was found that high costs were related to disposable devices being more expensive. In another study it is reported that significantly higher costs of the VATS procedure can limit widespread introduction of VATS lobectomy [19]. On the other hand, Burfeind et al. reported that VATS lobectomy is a cheaper procedure compared to posterolateral thoracotomy [20]. Swanson et al. also obtained similar findings in a multicentric study [21].

In a study by Casali and Walker who compared thoracoscopic and open resections, the cost of the thoracoscopic group was significantly lower. The highest outflow was caused by disposable devices. However, since hospital stay was shorter, the total cost of thoracoscopic resections was lower [22]. Sugi et al. compared 10 VATS lobectomies with 20 thoracotomies. The cost of disposables was found to be significantly higher in the VATS group. The length of hospital stay was the same and as a result the general cost of VATS lobectomies was found to be higher [23]. Park et al. compared the costs of open, thoracoscopic and robotic resections. The cost of robotic re- 
sections was higher compared to thoracoscopic and open resections. Nevertheless, they found that costs of thoracoscopic resections were lower compared to open resections [24].

According to these studies, the general cost of VATS or thoracotomy for lung resection is variable and the issue is controversial. It is clear that, with high disposable instrument costs where hospital stay between the groups is the same or it does not make any significant difference due to low bed fees, the total cost of VATS lobectomy would be higher. In a study reviewing the cost analysis reports, it is stated that the general cost of VATS procedures is higher. However, in studies between different countries where hospital stay duration, bed fees and disposable instrument costs vary, it is reported that no definitive conclusions could be drawn. Further prospective randomized studies are necessary to clarify the cost issue more precisely, and strategies of cost reduction should be developed [25].

In this study, we compared the costs and hospital stay durations of patients who underwent VATS or lobectomy with standard thoracotomy. The costs of main devices such as video and endoscopic equipment were excluded. Disposable devices and hospital service costs (intensive care, anesthesia, surgery, bed fees, etc.) were included. While hospital stay was significantly shorter in the VATS group than the thoracotomy group, the total cost was still higher. This is because of low bed costs and high costs of the disposable instruments that are used in VATS lobectomy.

The patient distribution was based on the surgeon's choice. Therefore, being a non-randomized retrospective study with a low number of patients was the biggest limitation of our study.

\section{Conclusions}

The most important factors that affect the total cost in thoracic surgery are the costs of hospital stay and the components required for patient care. In our country, bed costs are lower than those in other countries. Our study shows that low bed costs and high costs of disposable instruments in VATS lobectomy are the main factors responsible for the higher cost of VATS lobectomy. As a result, unlike western countries, in developing countries like ours, VATS resections cost more than thoracotomy. Time to return to work as one of the determinants of the economic outcome cannot be assessed accurately in Turkey as lung cancer pa- tients are accepted as retired (for at least 2 years) as soon as they apply to the social security system.

\section{Acknowledgments}

This work was presented as a poster (P-032) at the $19^{\text {th }}$ European Conference on General Thoracic Surgery, European Society of Thoracic Surgeons, in Marseille, France, between 5 and 8 June 2011, and was awarded with the ESTS-Dutch Society For Lung Surgery Annual Meeting Travel Grant 2011.

\section{References}

1. Jones RO, Casali G, Walker WS. Does failed video-assisted lobectomy for lung cancer prejudice immediate and longterm outcomes? Ann Thorac Surg 2008; 86: 235-9.

2. Da Silva MC, Swanson SJ. Video-assisted thoracic surgery. In: ACS surgery: principles \& practice. Ashley SW (ed.). Decker Publishing Ontario, Canada 2008; Sect 4/Chapter 10.

3. Bohanes T, Szkorupa M, Klein J, et al. Videothoracoscopic identification of chondromatous hamartoma of the lung. Videosurgery Mininv 2013; 8: 152-7.

4. Piwkowski C, Gabryel P, Kasprzyk M. Video-assisted thoracic surgery pneumonectomy: the first case report in Poland. Videosurgery Mininv 2012; 7: 197-201.

5. Jemal A, Siegel R, Ward E, et al. Cancer statistics, 2008. CA Cancer J Clin 2008; 58: 71-96.

6. Ginsberg R, Rubinstein LV. Randomized trial of lobectomy versus limited resection for T1 NO non-small cell lung cancer. Lung Cancer Study Group. Ann Thorac Surg 1995; 60: 615-22.

7. Yim AP. Cost-containig strategies in video-assisted thoracic surgery. An Asian perspective. Surg Endosc 1996; 10: 1198-200.

8. Ettinger DS, Akerley W, Bepler G, et al. Non-small cell lung cancer clinical practice guidelines in oncology. J Natl Compr Cancer Network 2008; 6: 228-69.

9. Onaitis MW, Petersen PR, Balderson SS, et al. Thoracoscopic lobectomy is a safe and versatile procedure: experience with 500 consecutive patients. Ann Surg 2006; 244: 420-5.

10. Swanson SJ, Herndon JE, D’Amico TA, et al. Video-assisted thoracic surgery (VATS) lobectomy. Report of CALGB 39802: a prospective, multi-institutional feasibility study. J Clin Oncol 2007; 25: 4993-7.

11. McKenna RJ, Houck W, Fuller CB. Video-assisted thoracic surgery lobectomy: experience with 1100 cases. Ann Thorac Surg 2006; 81: 421-6.

12. Demmy TL, Curtis JJ. Minimally invasive lobectomy directed toward frail and high-risk patients: a case control study. Ann Thorac Surg 1999; 68: 194-200.

13. Nagahiro I, Andou A, Aoe M, et al. Pulmonary function, postoperative pain, and serum cytokine level after lobectomy: a comparison of VATS and conventional procedure. Ann Thorac Surg 2001; 72: 362-5.

14. Villamizar NR, Darrabie MD, Burfeind WR, et al. Thoracoscopic lobectomy is associated with lower morbidity compared to thoracotomy. J Thorac Cardiovasc Surg 2009; 138: 419-25. 
15. Flores RM, Alam N. Video-assisted thoracic surgery lobectomy (VATS), open thoracotomy, and the robot for lung cancer. Ann Thorac Surg 2008; 85: S710-5.

16. Whitson BA, Groth SS, Duval SJ, et al. Surgery for early-stage non-small cell lung cancer: a systematic review of video-assisted thoracoscopic surgery versus thoracotomy approaches to lobectomy. Ann Thorac Surg 2008; 86: 2008-18.

17. Yan TD, Black D, Bannon PG, et al. Systematic review and meta-analysis of randomized and nonrandomized trials on safety and efficacy of video-assisted thoracic surgery lobectomy for early-stage non-small-cell lung cancer. J Clin Oncol 2009; 27: 2553-62.

18. Hazelrigg SR, Nunchuck SK, Landreneau RJ, et al. Cost analysis for thoracoscopy: thoracoscopic wedge resection. Ann Thorac Surg 1993; 56: 633-5.

19. Piwkowski C, Gabryel P, Gałęcki B, et al. High costs as a slow down factor of thoracoscopic lobectomy development in Poland - an institutional experience. Videosurgery Miniinv 2013; 8: 334-41.

20. Burfeind WR, Jaik NP, Villamizar N, et al. A cost minimisation analysis of lobectomy: thoracoscopic versus posterolateral thoracotomy. Eur J Cardiothorac Surg 2012; 37: 827-32.

21. Swanson SJ, Meyers BF, Gunnarsson CL, et al. Video-assisted thoracoscopic lobectomy is less costly and morbid than open lobectomy: a retrospective multiinstitutional database analysis. Ann Thorac Surg 2012; 93: 1027-32.

22. Casali G, Walker WS. Video-assisted thoracic surgery lobecto my: can we afford it? Eur J Cardiothorac Surg 2009; 35: 423-8.

23. Sugi K, Kaneda Y, Nawata K, et al. Cost analysis for thoracoscopy: thoracoscopic wedge resection and lobectomy. Surg Today 1998; 28: 41-5

24. Park BJ, Flores RM. Cost comparison of robotic, video assisted thoracic surgery and thoracotomy approaches to pulmonary lobectomy. Thorac Surg Clin 2008; 18: 297-300.

25. Van Schil P. Cost analysis of video-assisted thoracic surgery versus thoracotomy: critical review. Eur Respir J 2003; 22: 735-8.

Received: 8.12.2013, accepted: 18.05.2014. 